\title{
GESTÃO DA COOPERAÇÃO INTERNACIONAL PARA O DESENVOLVIMENTO SUL-SUL À LUZ DOS POSTULADOS E PRINCÍPIOS DA GESTÃO SOCIAL
}

\author{
Danielle Ullrich* \\ Rosinha Carrion * *
}

\begin{abstract}
O presente ensaio teórico discute a natureza das relações entre países no sistema internacional e suas respectivas implicações para a gestão de programas e projetos no campo da cooperação internacional para o desenvolvimento (CID), à luz dos postulados e princípios da gestão social. Parte-se do postulado que as ações de CID implicam processos de gestão e são influenciadas pela representação que o país doador faz do desenvolvimento, assim como pelas motivações que o levam a cooperar. A ciência da administração e, em particular a gestão social, tem muito a aportar para a compreensão dos resultados e revisão das práticas de gestão que acompanham as ações realizadas no campo da CID. A prática de impor e sobrevalorizar "saberes técnicos", em detrimento dos "saberes locais", técnicos e não técnicos, considerados inferiores, tem induzido a resultados desastrosos em termos políticos, econômicos e sociais.

Palavras-chave: Cooperação Internacional para o Desenvolvimento. Cooperação Sul-Sul. Gestão Social. Construção de saberes. Ecologia de Saberes.
\end{abstract}

\section{INTRODUÇÃO}

O presente ensaio teórico discute a natureza das relações entre países no sistema internacional e suas respectivas implicações para a gestão de programas e projetos no campo da cooperação internacional para o desenvolvimento. Parte-se do postulado que as ações de cooperação internacional implicam processos de gestão e são influenciadas pela representação que o país doador faz do desenvolvimento, assim como pelas motivações que o levam a cooperar.

Uma primeira aproximação permite descrever o campo da cooperação internacional para o desenvolvimento como um espaço de disputas entre os Estados, que, no período pós Guerra Fria, têm buscado consolidar sua posição política via o emprego de poder simbólico. A ciência da administração e, em particular, a gestão social, tem muito a aportar para a compreensão

* Instituto Federal de Santa Catarina (IFSC).

Av. Mauro Ramos, 950. Cep: 88020-300. Florianópolis Santa Catarina - Brasil. danielle_ullrich@yahoo.com.br

* * Universidade Federal do Rio Grande do Sul. Programa de Pós-Graduação em Administração (PPGA-EA/UFRGS).

Rua Washington Luiz, 855. Cep: 90010-460. Porto Alegre Rio Grande do Sul - Brasil. rosinha.carrion@ufrgs.br dos resultados das ações realizadas sob a lógica supra referida, uma vez que se dedica a estudar e a compreender as relações de poder.

No tradicional modelo de cooperação internacional Norte-Sul, para a aplicação dos programas e projetos nos países receptores, cria-se uma interface de atuação entre os operadores do desenvolvimento, provenientes de países centrais, e as populações-alvo, oriundas de países semiperiféricos e periféricos. Nesse âmbito, instauram-se tentativas de transferência de "saber-fazer", processo através do qual conjuntos de saberes, técnicos (oriundos de um sistema de saberes técnico-científicos cosmopolita e de origem ocidental) e populares (técnicos e não técnicos) (Sardan, 1995), com suas respectivas significações, geralmente, entram em confronto.

É por meio da imposição dos saberes científicos, tomados como verdade absoluta, que os países centrais exercem sua dominação sobre os países periféricos, sob a justificativa de cooperar para o desenvolvimento destes países. Todavia, com o avanço da globalização e o reordenamento do sistema internacional, os países semiperiféricos e periféricos, com 
a intenção de ganhar espaço e participar das discussões e decisões sobre temas de interesse global, têm adotado como estratégia as práticas de Cooperação Sul-Sul (CSS), as quais, em tese, propõem relações mais igualitárias e solidárias entre os países envolvidos. Ao tratar da questão, Milani (2012) aponta que boa parte do argumento político que sustenta a CSS fundamentase no pressuposto de que países semiperiféricos e periféricos podem e devem cooperar a fim de resolver seus próprios problemas políticos, econômicos e sociais com base em identidades compartilhadas (ex-colônias, status econômico, experiência histórica etc.), esforços comuns, interdependência e reciprocidade.

A questão que instiga a discussão proposta neste ensaio teórico parte de duas teses. A primeira aponta para a tendência à reprodução do autoritarismo que caracterizou, historicamente, a cultura política praticada no campo da Cooperação Norte-Sul, a qual tem como pressuposto de base o entendimento da superioridade técnica dos países do Norte sobre aqueles do Sul, o que daria aos primeiros o "direito" de impor como verdades absolutas às comunidades recipiendárias, ideias, postulados, práticas e medidas que beneficiam seus próprios interesses. Já a segunda, mais recente e, ainda, em construção, refere-se a um modelo de relações ontre países centrais, periféricos e semiperifériㄱ. cos, baseado em relações mais homogêneas e no Ф் respeito à diversidade histórica, cultural e econômica dos países envolvidos. Proposta esta, no seio da qual o conhecimento é entendido

\& privilegiando-se processos de construção con$\stackrel{\infty}{\sim}$ junta nas diferentes fases e etapas dos progra-

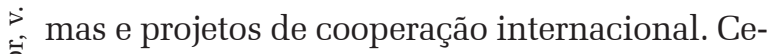
nário esse, no qual todos os países envolvidos, sejam centrais, periféricos e semiperiféricos, teriam mais a ganhar. O presente ensaio teórico tem por objeto de estudo a análise do tipo de relações que os países vêm estabelecendo entre si, no campo da cooperação internacional para o desenvolvimento, e suas respectivas implicações para o processo de construção transferência de saberes e, consequentemente, para o desenvolvimento. O que, iminentemente, significa relações de poder.

Ao compreender que as tradicionais teorias organizacionais, de cunho positivista e funcionalista, não dão conta de um debate que se situa no campo das relações de poder, o presente ensaio teórico busca - apoiado no referencial teórico dos estudos críticos e do pensamento neocolonial, que, em sua essência, remete ao campo da gestão social - contribuir para a transformação dos procedimentos de gestão que balizam as ações de CID. Para tanto, além da presente introdução, apresenta-se uma breve discussão sobre o campo da cooperação internacional para o desenvolvimento e expõe-se argumentos para adotar os princípios e postulados da gestão social para compreender o campo da cooperação internacional para o desenvolvimento. Ao que se segue um conjunto de considerações preliminares.

\section{O CAMPO DA COOPERAÇÃO IN- TERNACIONAL PARA O DESENVOL- VIMENTO}

A expressão cooperação internacional para o "desenvolvimento" (CID) remonta ao final da II Guerra Mundial e tem sido utilizada, de acordo com o posicionamento de teóricos da área de relações internacionais, como um instrumento político, cuja finalidade seria combater as dificuldades econômicas e sociais dos países periféricos.

Dois modelos, com alinhamentos distintos, têm sido discutidos pelos pesquisadores da referida área: o modelo de cooperação Centro-Periferia (Norte-Sul - CNS) e o modelo de cooperação entre Semiperiferia e Periferia (Sul-Sul - CSS). O debate sobre essas propostas perpassa questões relativas ao fenômeno da globalização, ao reordenamento mundial e à colonialidade dos saberes. 
Neste artigo, entende-se a cooperação internacional para o desenvolvimento como um campo, ou seja, uma estrutura de relações objetivas, cujos agentes têm disposições específicas, denominadas habitus. É a posição que os agentes ocupam nesta estrutura de relações objetivas que orienta, sem determinar as tomadas de posição definidas pela posse de capitais específicos (Bourdieu, 2004, 2012). O campo da cooperação internacional para o desenvolvimento começou a ser constituído no final da Segunda Guerra Mundial, influenciado pela disputa de poder em dois conflitos representados pelos eixos Norte-Sul e Leste-Oeste.

A dinâmica da cooperação Norte-Sul seria balizada pelo discurso de posse do presidente dos Estados Unidos, Harry S. Truman. De caráter profundamente dualista, o referido discurso dividiria o mundo entre, de um lado, os países autoclassificados "desenvolvidos" e, de outro, os por ele classificados de "subdesenvolvidos", cabendo aos países do "Norte”, ricos e "desenvolvidos", levar aos países do "Sul", pobres e subdesenvolvidos, as maravilhas do avanço científico e do progresso técnico e industrial por eles conquistados (Barbantine Junior, 2005).

Nesse período, ainda, o conflito Leste-Oeste instaurou a Guerra Fria, e o que estava em disputa no campo internacional era o alinhamento dos países aos blocos capitaneados por Estados Unidos e União Soviética. De acordo com Santos Filho (2005), os Estados classificados como "desenvolvidos" passariam a ajudar os Estados avaliados como "subdesenvolvidos”, sob o pretexto da cooperação internacional para o desenvolvimento, a sair da sua condição de miséria, desde que estes últimos seguissem o modelo ocidental das sociedades capitalistas. O ponto central era criar mecanismos para a modernização dos Estados, apontados como "subdesenvolvidos", conforme o modelo ocidental desenvolvimentista.

Dussel (2002) explica que o discurso desenvolvimentista indica a falácia de pretender um "desenvolvimento" igual para o "centro" e a "periferia", não percebendo que a "periferia” não está atrasada, mas que trata-se de uma posição assimétrica de dominado, condição imposta pelo discurso colonialista. Desse modo, o "atrasado", o periférico poderá continuar o caminho do "industrializado", do centro, e chegar a se desenvolver, enquanto que o "explorado", por mais que trabalhe, nunca será "livre" porque a sua própria subjetividade dominada inclui a relação com o dominador. Os modernizadores da periferia são desenvolvimentistas porque não percebem que deve ser superada a própria relação de dominação em escala mundial, como pré-requisito para o "desenvolvimento nacional”.

Percebendo a disputa, no campo internacional, entre os países do Norte e buscando uma alternativa para equilibrar os efeitos perversos das relações Norte-Sul (Puente, 2010), os países do Sul reuniram-se em abril de 1955, na Conferência Ásia-África, realizada em Bandung, Indonésia, para apresentar aos países avaliados como "desenvolvidos", problemas relativos ao desenvolvimento. Formou-se, então, o Movimento dos Não Alinhados, que buscava por uma reforma no sistema econômico internacional, cujo clímax ocorreu na Conferência das Nações Unidas para o Comércio e Desenvolvimento (UNCTAD), em 1964, e culminou com a formação do Grupo dos 77. (Puente, 2010; Esteves et al., 2012; Abreu, 2012).

Conforme Puente (2010), o Grupo dos 77 reunia países semiperiféricos e periféricos interessados em reforçar sua posição mediante a identificação de pontos de interesse comum e da proposição de medidas concretas que pudessem alterar as condições do comércio internacional, consideradas como desvantajosas para os países do Sul. O próprio modelo de cooperação para o desenvolvimento passou, também, a ser questionado, por estar assentado sobre bases ora assistencialistas, ora de dominação, submetidas a interesses comerciais dos países do centro.

Diante desse contexto, os diálogos, discussões e formações de coalizações em prol da 
cooperação Sul-Sul avançaram. Segundo Xalma (2011), em 1977, durante a $32^{\text {a }}$ Sessão da Assembleia Geral das Nações Unidas, pela primeira vez, uma resolução adotada nesta sessão buscou definir os objetivos da então chamada CTPD (Cooperação Técnica entre Países em Desenvolvimento) e seus princípios iniciais. A intenção era promover as alianças nacionais entre os chamados países em desenvolvimento. Em 1978, sob a égide das Nações Unidas, 138 países reuniram-se e adotaram o Plano de Ação de Buenos Aires (BAPA), cuja finalidade era promover e implementar a CTPD. Conforme Puente (2010), a Conferência de Buenos Aires representou o primeiro esforço coletivo de identificação e de sistematização das formas, modalidades e possibilidades de cooperação entre países em desenvolvimento.

De acordo com Cervo (2010) e Puente (2010), o BAPA instituiu uma nova modalidade de cooperação, a CTPD, a qual não buscava substituir os tradicionais programas de cooperação, bilaterais ou multilaterais, mas a eles acrescentar, permitindo que os países em desenvolvimento pudessem aproveitar suas capacidades e superar as relações de dependência existentes na tradicional cooperação Norte-Sul. Conforme Xalma (2011), o BAPA definiu a CTPD como "um processo conscien욜 te, sistemático e politicamente motivado", caจั racterizado pelos princípios de: não ingerência Фं nos assuntos internos de outras nações por países cooperantes; igualdade entre os parceiros; o respeito para com o nível local de desenvolvimento de cada país.

Após os avanços nas discussões relativas à CSS na década de 1970, Puente (2010) afirma que, nos anos 1980, não houve avanços, devido à crise da dívida financeira que atingiu, em especial, os países semiperiféricos, que não conseguiram financiar os projetos de cooperação. Por imposição do FMI, o período após a chamada "década perdida" foi acompanhado da implementação de programas de ajustamento ortodoxos, com cortes nas despesas públicas, fazendo com que o espaço para financiar iniciativas de desenvolvimento fosse muito exíguo. Além das dificuldades econômicas, um número muito restrito de países semiperiféricos dispunha de recursos para implementar projetos de cooperação para o desenvolvimento.

A partir da década de 1990, com a aceleração da globalização, novos desafios surgiram para a CSS e passaram a exigir de todos os países, mais especialmente dos semiperiféricos, a busca por novas formas de inserção na arena internacional. A CSS seria um dos mecanismos inovadores de interdependência para minimizar os riscos adjacentes ao processo de globalização e maximizar as oportunidades advindas desse processo. Em especial, por recomendação do PNUD e, também, pela iniciativa de alguns países do Sul, reforçou-se o discurso da CSS nos foros internacionais, o que pôde ser percebido por meio das diversas conferências internacionais realizadas sobre o tema, a partir dos anos 2000 (Puente, 2010).

As discussões relativas à modalidade de CSS a consolidaram como uma modalidade de cooperação que contempla três dimensões: (i) dimensão política, que promove a constituição de âmbitos autônomos para a geração de perspectivas e práticas alternativas entre países semiperiféricos e periféricos; (ii) dimensão técnica, processo pelo qual países semiperiféricos e periféricos adquirem capacidades individuais e coletivas através de intercâmbios cooperativos em conhecimentos, experiências tecnológicas, expertises tecnológicas, que se traduzem em projetos e programas de cooperação; (iii) dimensão econômica, realizada no âmbito comercial, financeiro e de investimentos entre países semiperiféricos e periféricos (Ayllón Pino, 2012).

Ao contemplar essas dimensões, Puente (2010) e Esteves et al. (2012) afirmam que a CSS configura-se ora como estratégia alternativa, ora como complementar e não necessariamente excludente à cooperação tradicional, CNS. Tal proposição está de acordo com os compromissos assinados durante as Conferên- 
cias Internacionais realizadas nos anos 2000 (Esteves et al., 2012).

Pode-se afirmar, também, que o fortalecimento da cooperação Sul-Sul é reflexo das alterações na política internacional, conforme apontam Pinheiro e Milani (2012): o multilateralismo, a importância assumida por países intitulados emergentes na arquitetura da nova ordem mundial, bem como o declínio de uma fase de mais de duzentos anos de ocidentalização mundial. Todavia, neste cenário de mudanças na ordem internacional e de "[...] emergência de novos Estados promotores da bandeira da CSS, parece se impor um olhar mais cuidadoso, analítico e empírico sobre essa realidade da cooperação" (Milani, 2012, p. 224).

Este cenário mundial instável implica diretamente sobre os debates que envolvem as modalidades de cooperação "Norte-Sul" ou centro-periferia e "Sul-Sul" ou semiperiferia e periferia, e influencia o sentido que caracteriza essas perspectivas de cooperação quanto ao processo de desenvolvimento. Ao pensar a cooperação internacional para o desenvolvimento como um campo de disputa, entende-se que a configuração do sistema mundial, que está engendrada no imaginário da sociedade mundial, é difícil de ser rompida, em especial porque os países centrais buscam manter seus capitais para sustentar sua posição hegemônica no jogo. Assim, reproduz-se, continuamente, no imaginário global, a divisão do mundo entre países considerados desenvolvidos e países avaliados como subdesenvolvidos (Ullrich, 2014).

Isto é possível vislumbrar, por exemplo, na área econômica, em que os países semiperiféricos e periféricos continuam sendo fornecedores de mão de obra e de recursos naturais para os países centrais, perpetuando a divisão internacional do trabalho e reforçando a lógica do moderno sistema-mundo, conforme aponta Wallerstein (2004). Na área política, apesar dos esforços em angariar espaços de discussão com os países centrais, ainda são poucas as possibilidades de participação dos países semiperiféricos e periféricos em organizações como a
ONU e o FMI, embora existam evoluções como a criação do G20. Na área do conhecimento, uma das condições para se avaliar o desenvolvimento, ainda verifica-se um predomínio dos saberes euro-norteamericanos sobre os saberes locais dos países semiperiféricos e periféricos. (Ullrich, 2014).

Por outro lado, a cooperação "Sul-Sul" aparece, no discurso, como um tipo de cooperação em que ambos se beneficiam. O que, na prática, nem sempre é verdade. Ou seja, o modelo mental engendrado no imaginário da sociedade mundial, que divide o mundo entre dominadores e dominados, também está presente nas práticas da Cooperação Sul-Sul. Ou seja, a modalidade de CSS não é uma alternativa que soluciona o problema da dominação eurocêntrica, uma vez que serve como um instrumento para alguns países do Sul angariar o aumento de capitais econômicos, políticos, sociais e culturais, com vistas a causar impacto na ordem do sistema mundial, buscando posições de destaque neste campo. A julgar pela ascensão e maior influência de países como Brasil, Índia, Rússia, China e África do Sul, tendo em vista o maior espaço para participação desses países nos fóruns mundiais nos últimos anos, acredita-se que, de fato, a modalidade de cooperação Sul-Sul possa ter contribuído para um maior protagonismo dos países do "Sul" no sistema mundial (Ullrich, 2014).

Entretanto, a discussão que envolve as modalidades de cooperação internacional para o desenvolvimento é muito mais complexa do que isto. Não se pode generalizar e afirmar que a modalidade de cooperação Sul-Sul sempre promova práticas dialógicas, que beneficiem ambos os parceiros, como vem sendo conceituada. Como exposto, na prática, muitas vezes reproduz-se o modelo de dominação, mesmo sem ter a intenção para a tal, pois é este modelo que se perpetua no imaginário da população mundial. O modelo da matriz colonial de poder eurocêntrico, evidenciado nos estudos de Quijano (2005).

A partir do debate proposto, entende-se 
que a cooperação internacional para o desenvolvimento pode ser compreendida como um instrumento utilizado pelos países para ganhar projeção política no campo internacional e ganhar poder de barganha nas instituições multilaterais. Pode-se pensar, então, na cooperação internacional como uma estratégia de gestão das relações estabelecidas no campo da cooperação internacional com vistas a aumentar o capital simbólico dos países. Posto isto, propõe-se discutir a cooperação internacional para o desenvolvimento à luz dos postulados e princípios da gestão social.

\section{POR UMA GESTÃO SOCIAL DA CO- OPERAÇÃO INTERNACIONAL PARA O DESENVOLVIMENTO SUL-SUL}

Diante do incômodo com a instrumentalização do conceito de gestão, e por compreender a cooperação internacional para o desenvolvimento como uma estratégia dos países para buscar poder e projeção no campo internacional, este ensaio teórico busca, no conceito de gestão social, uma possibilidade de compreender a gestão da cooperação internacional para o desenvolvimento a partir de sua dimensão política.

Entende-se que: a) o campo da cooperação internacional para o desenvolvimento é complexo, e que a gestão deste campo não pode ser apenas técnica, mas também implica uma relação de forças em suas dimensões econômica, política e social; b) as tradicionais teorias da administração de base eurocêntrica não conseguem explicar as diferentes realidades econômicas, políticas e sociais dos países inseridos no sistema internacional; c) o conceito de gestão social está em construção e possui amplo campo de debate que abarca as dimensões econômica, política e social; neste artigo, adota-se o conceito de gestão social para compreender a gestão da cooperação internacional para o desenvolvimento.

O conceito de gestão social vem sendo formulado por um movimento de pesquisadores brasileiros que, desde a década de 1990, vem se debruçando sobre esta temática e, principalmente, a partir da segunda metade da primeira década deste século, com a criação de programas de pesquisa, encontros especializados e editoração de periódicos dedicados ao tema (Cançado; Tenório; Pereira, 2011).

Todavia, durante mais de vinte anos de debates, ainda não há um consenso sobre o conceito e os princípios da gestão social. Martins e Carrion (2012) ressaltam que diversos pesquisadores como Tenório, França Filho, Fischer, Schommer, Boullosa, Carrion entre outros, têm trabalhado no intuito de definir o campo e a lógica de atuação da gestão social. Alguns autores a tratam sob uma perspectiva ampla (demandas e necessidades do social), outros a vinculam a uma problemática mais micro (aproximando-a da gestão pública).

Tenório (2006) entende a gestão social como o processo gerencial dialógico em que a autoridade decisória é compartilhada entre os participantes da ação. O adjetivo 'social' qualificando o substantivo 'gestão' é percebido como o espaço privilegiado de relações sociais em que todos têm direito à fala, sem nenhum tipo de coação. A definição de gestão social, ainda para o autor, está apoiada no conceito de cidadania deliberativa, a qual propõe que a legitimidade das decisões deve ter origem em espaços de discussão orientados pelos princípios da inclusão, do pluralismo, da igualdade participativa, da autonomia e do bem comum. Assim, o autor entende a gestão social como o processo gerencial decisório deliberativo que procura atender às necessidades de uma sociedade, região, território ou sistema social específico, quer vinculado à produção de bens, quer à prestação de serviços.

Tenório apoia-se teoricamente em Jürgen Habermas, filósofo e sociólogo alemão, e seu conceito de ação comunicativa. Entretanto, a teoria de Habermas é escrita a partir do contexto alemão, preocupado com o reestabelecimento dos vínculos entre o socialismo e a 
democracia. Portanto, sem a devida redução sociológica, não poderíamos nos embasar no conceito de Habermas para compreender o campo da gestão social.

França Filho (2008) afirma que a gestão social diz respeito a um modo de gestão próprio às organizações, atuando num circuito que não é originariamente aquele do mercado e do Estado. É o espaço próprio da chamada sociedade civil, portanto, uma esfera pública de ação que não é estatal. As organizações, atuando neste âmbito, não perseguem objetivos econômicos. O econômico aparece, apenas, como um meio para a realização dos fins sociais, que podem definir-se, também, em termos culturais (de promoção, resgate ou afirmação identitária etc.), políticos (no plano de uma luta por direitos etc.) ou ecológicos (em termos de preservação e educação ambiental etc.), a depender do campo de atuação da organização. A intencionalidade econômica aparece, apenas, como um meio para a realização de fins sociais, culturais, políticos ou ecológicos. É exatamente esta inversão de prioridades em relação à lógica da empresa privada que condiciona a especificidade da gestão social.

França Filho desenvolve seu conceito de gestão social baseado na ótica de gestão como um processo, a partir da Teoria de Fayol, segundo a qual a gestão é processo de planejar, organizar, dirigir e controlar. A interpretação do conceito de gestão social tenta absorver tanto a dimensão de processo ou meio (como opera a gestão), quanto aquela da finalidade (quais os objetivos da gestão). Para tanto, deve-se considerar dois níveis de análise ou de percepção da gestão social: de um lado, aquele que a identifica a uma problemática de sociedade (nível societário), do outro, aquele que a associa a uma modalidade específica de gestão (nível organizacional). Quanto ao nível societário, o autor chama a atenção para a existência de uma dinâmica política de auto-organização social, através de diferentes modalidades do fato associativo, cujo papel deve ser valorizado num processo de democratização da sociedade. Como modo de orientação para uma ação organizacional, a gestão social diz respeito a uma forma de gestão organizacional que, do ponto de vista da sua racionalidade, pretende subordinar as lógicas instrumentais a outras lógicas mais sociais, políticas, culturais ou ecológicas (França Filho, 2008).

A partir destas proposições, o conceito de gestão social elaborado por França Filho apoia-se tanto no conceito de espaço público, estatal ou societário, bem como no conceito econômico de reciprocidade e redistribuição, com base nos estudos do filósofo e historiador de economia, o austríaco Karl Polanyi. Para França Filho (2008), a discussão sobre gestão social insere-se numa perspectiva de reconciliação entre o econômico e o social.

Schommer e França Filho (2008) ressaltam a proposta teórica construída no artigo de França Filho (2008), ao conceber o termo gestão social a partir de um processo, sendo um meio ou uma finalidade. Entretanto, pautam a discussão da gestão social pela inserção das teorias de aprendizagem, ao afirmarem que:

\begin{abstract}
A ideia de gestão social, por sua vez, está mais afinada com a abordagem social da aprendizagem, que enfatiza as interações sociais que ocorrem entre as pessoas como bases da aprendizagem, tanto coletiva quanto individual. Associando essa questão à formação em gestão social, o desafio não se resume, pois, a aprimorar capacidades individuais, mas gerar instrumentos e metodologias capazes de aprimorar capacidades de todos os envolvidos no processo de gestão. (Schommer; França Filho, 2008, p. 65).
\end{abstract}

Tal aproximação teórica é reforçada no trabalho de Boullosa e Schommer (2009), ao alinhar o conceito de gestão social com a abordagem social da aprendizagem. Para as autoras, o desafio da gestão social seria a construção conjunta de instrumentos e metodologias aptos a aprimorar capacidades de todos os envolvidos em processos de gestão social, já que são processos coletivos, em que todos participam da construção. Para elas, o processo de formação em gestão social deve estar baseado na articulação entre diferentes saberes, 
que tendem a ser potencializados em situações que envolvem práticas concretas, em torno das quais as pessoas se engajam, levando saberes que já possuem e construindo outros, coletivamente. Trata-se, pois, de construir processos de formação que valorizem e estimulem a articulação entre saberes acadêmicos e não acadêmicos, multi e interdisciplinares, de diferentes atores, com diferentes histórias, origens e áreas de atuação. Tais pressupostos aliam-se à proposta da ecologia dos saberes de Sousa Santos (2008), entendida como um conjunto de práticas que promovem uma convivência ativa de saberes e que apela a saberes contextualizados, situados e úteis.

As autoras, Boullosa e Schommer (2009) criticam, ainda, a formulação do conceito de gestão social. Para elas, na medida em que é assumido por diferentes escalas e escolas, o conceito começa a perder seu caráter de processo de inovação, que acolhe diferentes e pontuais experiências, em favor de uma nova interpretação que tende a considerá-la como produto inovador. Ao institucionalizar-se enquanto campo de gestão e enquanto modo de gerir, a gestão social pode ter perdido parte da riqueza do processo que a fundou. Além disso, a comparação com o campo da administração pública pode ter acelerado o processo de preciเ s sar relações e criar leis, minando, ainda mais, ثे sua capacidade de construir-se como modelo Ф્ alternativo à abordagem paradigmática neo这 clássica, ainda subjacente ao campo da admiì nistração pública. pela ciência administrativa, e o que deve ser efetivamente constituído, resguardando, desse modo, o reconhecimento da especificidade, em termos de racionalidade, do universo da gestão social. (Boullosa; Schommer, 2009). A construção teórica das autoras discute o diálogo entre o reconhecimento de diferentes saberes, a partir da obra de Sousa Santos, bem como o conceito de aprendizagem social, a partir das elaborações teóricas de Étienne Wenger.

Para Fischer (2007), o cenário no qual se constroem as práticas de gestão social é formado pela globalização da economia, reformas estatais, problemas socioambientais, violência e pobreza, fenômenos mundiais que contribuem para uma revisão do papel dos gestores, estejam eles atuando no mercado, no Estado ou em organizações da sociedade civil sem fins lucrativos. A autora entende a gestão social como o "ato relacional capaz de dirigir e regular processos por meio da mobilização ampla de atores na tomada de decisão (agir comunicativo) que resulte em parcerias intra e inteorganizacionais, valorizando as estruturas descentralizadas e participativas, tendo como norte o equilíbrio entre a racionalidade em relação a fins e em relação a valores, alcançar enfim um bem coletivamente planejado, viável e sustentável a médio e longo prazo. O conceito de gestão social de Fischer (2007) aproxima estrategicamente a gestão e a sociedade.

Em outro trabalho, Fischer et al. (2006) argumentam que, ao tratar de gestão social, articula-se liderança e management, eficácia, eficiência e efetividade social. Estamos tratando de mediações sociais realizadas por indivíduos (gestores) e suas organizações. Deste modo, o campo de gestão social ou gestão do desenvolvimento social é um reflexo das práticas e do conhecimento construído por muitas disciplinas, delineando-se uma proposta multiparadigmática e de natureza interdisciplinar. Como as ações mobilizadoras partem de múltiplas origens e têm muitas direções, as dimensões ‘teórica' e 'prática' estão emaranhadas - aprende-se com as práticas, e o conhecimento se organiza para iluminar as práticas. A gestão do desenvolvimento é uma forma de gestão social, a transição entre modelos do século passado e novas formas, comprometidas com utopias de desenvolvimento local, que os tempos de crise fazem emergir.

Carrion (2009), ao discutir a contribui- 
ção da gestão social para o desenvolvimento, em uma mesa redonda do XI Colóquio Internacional sobre o Poder Local, começa por advertir que, embora aparentemente o local e o global sejam dois níveis distintos e separados, as decisões que se produzem no global repercutem diretamente no local, influenciando, de modo decisivo e de forma contundente, aquilo que tentamos realizar em nossas comunidades.

A autora parte de um traçado histórico em âmbito mundial, com base nas teorias desenvolvimentistas, para entender o cenário em que é construído o conceito de gestão social. E chega à conclusão que as discussões sobre a gestão social aparecem em um cenário em meio ao qual as necessidades humanas mais básicas são brutalmente submetidas aos interesses econômicos das empresas, em nome da ideologia da competitividade (Carrion, 2009).

Para ela, a gestão social vem sendo empurrada por um duplo movimento: de um lado, aqueles que a percebem como uma estratégia, como um conjunto de diretrizes ou, ainda, como modo de coordenação, de planejamento e de direção das ações com vistas à humanização do processo de geração de riqueza sob o regime de acumulação capitalista. E, de outro, a visão de que outro mundo é possível, conforme o slogan dos Fóruns Sociais Mundiais, que defendem a necessidade de uma revolução política. Uma revolução, de um modo geral, distinta da concebida sob a influência do marxismo tradicional, na medida em que não remete à luta de classes, mas à criação de outras formas e outras modalidades de produção e relação social, calcadas na solidariedade, na valorização do trabalho e na autogestão, concomitantemente ao modelo capitalista. Não se trata, pois, de substituir um modelo, o capitalista, por outro, de viés solidário, mas de convivência simultânea (Carrion, 2009).

Deste modo, o constructo do conceito de gestão social poderia seguir por dois caminhos: um, pautado pela humanização do capitalismo; e outro, pautado por uma revolução política, ainda que pacífica. Ou, quem sabe, ainda, po- deria alinhar-se à construção de um novo mundo, sem definições à priori, num processo de abertura ao novo, de respeito à diversidade, de busca de uma nova epistemologia dos saberes, conforme propôs Sousa Santos, sem abdicar-se da capacidade de se indignar e/ou de abandonar a luta por justiça (Carrion, 2009).

Portanto, para Carrion (2009), a gestão social se constitui em meio a uma disputa política pelo modelo de sociedade e de ordem mundial sob o qual almejamos viver, assim como ela atende à necessidade de articular, de atar, sob o novo cenário nacional e internacional, as pontas desatadas dos movimentos sociais; do debate desenvolvimento versus crescimento econômico; da necessidade de se tomar medidas para fazer frente à crise ambiental, assim como à necessidade de aportar suporte teórico e de criar um espaço de intermediação, de diálogo, entre, de um lado, a reflexão sobre a cidadania e os direitos humanos e, de outro, a questão econômica e a promoção do crescimento econômico dado, que, dissociadas, nenhuma das duas abordagens dá conta do problema de construção de uma ordem social minimamente sustentável.

Nesse sentido, Carrion (2009) conclui afirmando que a gestão social introduziu uma verdadeira revolução simbólica no campo da gestão. Pensada enquanto espaço de luta política em defesa dos princípios de justiça, igualdade, respeito à diferença e à natureza, ela acena com a possibilidade de se consolidar uma nova fala, o que introduz uma revolução objetiva, concreta no modo de se pensar e fazer o desenvolvimento. A gestão social remete a um campo de conhecimento. Isto é, a um "território” de resistência política e de construção/ difusão de um modelo de sociedade e de luta pela consolidação de uma ordem social coerente com uma visão complexa de desenvolvimento. Conforme Carrion (2012), a gestão social visa resgatar a dimensão política e de emancipação do sujeito.

Nesse sentido, o debate pode contribuir para a compreensão da cooperação internacio- 
nal para o desenvolvimento pensada enquanto uma estratégia utilizada para conquistar espaço no campo internacional. Ao pautarem-se pela CSS, os países semiperiféricos e periféricos introduzem uma pequena revolução política no sistema, alterando a configuração de poder entre os países no jogo internacional.

\section{CONSIDERAÇÕES FINAIS}

No presente artigo, à luz dos estudos críticos e do pensamento neocolonial, refletimos sobre a potencial contribuição da Gestão Social para o campo da Cooperação Internacional para o Desenvolvimento, à luz de um conjunto de proposições teóricas, entre as quais merecem destaque: a noção de transmodernidade, que propõe a articulação das culturas subalternas, com aquilo que é não eurocêntrico, a partir da categoria exterioridade (Dussel, 2002); a colonialidade do poder, como dimensão constitutiva da modernidade, que estabelece relações assimétricas de poder que modelam o mundo capitalista e o padrão mundial de poder, ao criar uma "matriz de poder colonial” (Quijano, 2005); o eurocentrismo, que, ao longo da formação do sistema moderno/colonial, institui uma verdadeira colonização epistemológica, eurocêntrica, que s subalterniza saberes, povos e culturas (Mignolo, ป 2005; Lander, 2005); a ocidentalização da ideia Фं de colonizado (Catro-Gómes, 2005); a ecologia dos saberes, por permitir pensar a diversidade e os a pluralidade, assegurando a coexistência de sa- dem social coerente com uma visão de mundo, de cidadania e de desenvolvimento baseada nos princípios defendidos por Sousa Santos (2008) na Ecologia dos Saberes.

Ao tratar da CID como um campo de disputa, no qual os países buscam projeção no cenário internacional por meio do uso de poder simbólico, aproximamos este debate ao campo da Ciência da Administração, que discute as relações de poder. Os debates sobre cooperação "Norte-Sul" ou centro-periferia e "Sul-Sul" ou semiperiferia e periferia, perpassam o sentido que caracteriza essas perspectivas de cooperação quanto ao processo de desenvolvimento. Ao pensar a CID sob a perspectiva Norte-Sul, reconhece-se que os países semiperiféricos e periféricos ainda sofrem a influência exercida pelos países centrais, num viés de dominação eurocêntrica nas áreas econômica, política, social e cultural. Por outro lado, o modelo de cooperação "Sul-Sul”, no qual os países periféricos e semiperiféricos estabelecem redes de cooperação, estaria, segundo Xalma (2011), reforçando as capacidades entre os parceiros em uma relação horizontal em que ambos se beneficiariam. Nesse sentido, as relações de cooperação "Sul-Sul" caracterizar-se-iam por um processo mais participativo, dialógico, compreendendo os diferentes sujeitos sociais de modo a resgatar a dimensão política e a possibilidade de emancipação dos sujeitos.

Todavia, na prática, nem sempre é isso que se verifica. Não se pode eleger a modalidade de Cooperação Sul-Sul como uma modalidade que supera a questão da dominação, tão engendrada no seio da sociedade moderna. Em alguns estudos de cooperação internacional entre um país semiperiférico e outro periférico, evidencia-se que o modelo de dominação eurocêntrico, é reproduzido, mesmo sem intenção, como, por exemplo, o caso de cooperação entre Brasil e Cabo Verde, apresentado por Ullrich e Carrion na tese intitulada "A "construção de saberes no campo da cooperação internacional sul-sul à luz dos postulados e princípios da gestão social”. Nesse sentido, 
entende-se que não se pode generalizar, pois as práticas de cooperação são eventos complexos, que envolvem diferentes visões de mundo.

Todavia, o que se pode ressaltar é que os países semiperiféricos e periféricos buscam espaço no campo internacional mediante a estratégia da CSS. Tais países introduzem uma pequena revolução política, ao estabelecer relações de resistência com os países centrais, buscando um espaço no campo internacional. E é por isso que entendemos que os postulados e princípios da Gestão Social, compreendida com base nas proposições teóricas suprarreferidas, podem contribuir para o entendimento da gestão da cooperação internacional para o desenvolvimento.

Assim sendo, neste artigo, compreendemos a gestão social da cooperação internacional para o desenvolvimento como uma prática de luta e de resistência, com vistas a uma mudança na ordem social, que supere o modelo de cooperação ocidental e eurocêntrico ao buscar articular diferentes saberes, conhecimentos, habilidades e competências, com base em uma visão de desenvolvimento adequada às realidades locais.

Por fim, diante do objetivo do presente estudo, que buscou analisar o tipo de relação que os países vêm estabelecendo entre si no campo da cooperação internacional para o desenvolvimento e suas respectivas implicações para o processo de construção transferência de saberes e, consequentemente, para o desenvolvimento, não pretendemos esgotar o debate. Este artigo é um convite para observarmos a aproximação entre o campo da cooperação internacional para o desenvolvimento com o campo das Ciências da Administração e as contribuições advindas do campo da Gestão Social, ao compreendê-la como um território de resistência para analisar as relações estabelecidas entre os países. Novos debates devem serão traçados para uma melhor compreensão deste enigma. Recebido para publicação em 17 de agosto de 2014
Aceito em 02 de dezembro de 2014

\section{REFERÊNCIAS}

ABREU, A. F. V. de. A Cooperação Sul-Sul e a atual dinâmica da Ajuda Internacional para o Desenvolvimento. In: Seminário Nacional de Pós-Graduação em Relações Internacionais, 1, 2012, Brasília. Anais... Brasília, 2012.

AYLLÓN PINO, B. Transformações globais, potências emergentes e cooperação sul-sul: desafios para a cooperação europeia. Caderno CRH, Salvador, v. 25, n. 65, p. 233-249, maio/ago. 2012.

BARBANTINE JUNIOR, Olympio. Desenvolvimento e Relações Internacionais. In: CAMPOS, Taiane Las Casas (org.) Desenvolvimento, desigualdades e relações internacionais. Belo Horizonte: Ed. PUC de Minas, 2005. p.141-169.

BOULLOSA, Rosana de Freitas; SCHOMMER, P. C. Gestão social: caso de inovação em políticas públicas ou mais um enigma de Lampedusa? In: RIGO, A. S.; SILVA JR., J. T.; SCHOMMER, P. C.; CANÇADO, A. C.(orgs.) Gestão social e políticas públicas de desenvolvimento: ações, articulações e agenda. Recife: UNIVASF, 2009.

BOURDIEU, P. Os usos sociais da ciência: por uma sociologia clínica do campo científico. São Paulo: Ed. UNESP, 2004.

\section{Brasil, 2012.}

O poder simbólico. 16. ed. Rio de Janeiro: Bertrand

CANÇADO, Airton Cardoso; TENÓRIO, Fernando G.; PEREIRA, José Roberto. Gestão social: reflexões teóricas e conceituais. Cadernos Ebape (FGV), v. 9, n. 3, Rio de Janeiro, Set. 2011, p. 681-703.

CARRION, Rosinha M. Seminário Sociologia da Globalização. Porto Alegre: UFRGS, 2012. Anotações de aula.

A Contribuição da Gestão Social para o

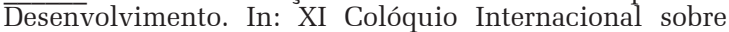
o Poder Local: Desenvolvimento e Gestão Social de Territórios, Salvador, 2009. Anais... Salvador: Universidade Federal da Bahia, 2009.

CASTRO-GÓMEZ, Santiago. Ciências sociais, violência epistêmica e o problema da invenção do outro. In: LANDER, Edgardo (Org.). A colonialidade do saber: eurocentrismo e ciências sociais - perspectivas latinoamericanas. Colecciûn Sur Sur, CLACSO, Ciudad Autônoma de Buenos Aires, Argentina. Setembro, 2005, p. 80-87.

CERVO, A. L. Brazil's rise on the international scene: Brazil and the world. Revista Brasileira de Política Internacional, Brasília, DF, v. 53, n. Especial, p. 7-32, 2010.

DE SARDAN, J. P. O. Antropologie et development: essai en socio-antropologie du chagement social. Paris: Karthala, 1995.

DUSSEL, Enrique. Ética da libertação na idade da globalização e da exclusão. Petrópolis: Vozes, 2002. p. 18-99.

ESTEVES,P.;ABREU,A.;FONSECA, J.;NIV,A.;ASSUNĈ̃O, M.; URIAS, F. A cooperação para o desenvolvimento, os BRICS e a política externa brasileira. In: JACOB, O. (ed.) Economia, parlamentos, desenvolvimento e migrações: as novas dinâmicas bilaterais entre Brasil e Europa. Rio de Janeiro: Konrad-Adenauer-Stiftung, 2012.

FISCHER, T. et al. Perfis visíveis na gestão social do desenvolvimento. Revista de Administração Pública, v. 40, n. 5 , set/out. 2006 .

. O futuro da gestão. HSM Management, v.10, n. 64, setembro-outubro 2007.

FRANÇA FILHO, G. C. Definindo gestão social. In: SILVA JÚNIOR, J. T.; MASIH, R. T.; CANÇADO, A.C.; SCHOMMER, P. C. (Orgs.). Gestão social: práticas em debate, teorias em construção. Fortaleza: Imprensa Universitária UFC, 2008. 
LANDER, Edgardo. Ciências sociais: saberes coloniais e eurocêntricos. In: LANDER, Edgardo (Org.). A colonialidade do saber: eurocentrismo e ciências sociais - perspectivas latino-americanas. Colecciûn Sur Sur, CLACSO, Ciudad Autônoma de Buenos Aires, Argentina. Setembro, 2005, p. 8-23.

MARTINS, B. V.; CARRION, R. M. Gestão Social: um olhar a partir de Perspectivas Latino-Americanas. In: EnAPG 2012, Salvador, novembro 2012. Anais... Salvador: ANPAD, 2012.

MIGNOLO, Walter D. A colonialidade de cabo a rabo: o hemisfério ocidental no horizonte conceitual da modernidade. In: LANDER, Edgardo (Org.). A colonialidade do saber: eurocentrismo e ciências sociais - perspectivas latino-americanas. Colecciûn Sur Sur, CLACSO, Ciudad Autônoma de Buenos Aires, Argentina. Setembro, 2005, p. 33-49.

MILANI, C. R. S. Aprendendo com a História: críticas à experiência da Cooperação Norte-Sul e atuais desafios à Cooperação Sul-Sul. Caderno CRH, Salvador, v. 25, n. 65, p. 211-231, maio/ago. 2012.

PINHEIRO, L.; MILANI, C.R.S. Introdução. In: PINHEIRO, L.; MILANI, C.R.S. (Orgs.). Política externa brasileira: as práticas da política e a política das práticas. Rio de Janeiro: Editora FGV, 2012, p. 13-30.

PUENTE, C. A. I. A cooperação técnica horizontal brasileira como instrumento de política externa: a evolução da cooperação técnica com países em desenvolvimento CTPD- no período 1995-2005. Brasília: FUNAG, 2010

QUIJANO, Aníbal. Colonialidade do poder, eurocentrismo e América Latina. In: LANDER, Edgardo (Org.). A colonialidade do saber: eurocentrismo e ciências sociais
- perspectivas latino-americanas. Colecciûn Sur Sur, CLACSO, Ciudad Autônoma de Buenos Aires, Argentina. Setembro, 2005, p. 107-130.

SANTOS FILHO, Onofre dos. O fogo de Prometeu nas mãos de Midas: desenvolvimento e mudança social. In: CAMPOS, Taiane Las Casas (org.) Desenvolvimento, desigualdades e relações internacionais. Belo Horizonte: Ed. PUC de Minas, 2005. p. 13-75.

SCHOMMER, P. C; FRANCA FILHO, G. C. Gestão Social e Aprendizagem em Comunidades de Prática: interações conceituais e possíveis decorrências em processos de formação. In: SILVA JÚNIOR, J. T.; MASIH, R. T. CANÇADO, A.C.; SCHOMMER, P. C. (Orgs.). Gestão social: práticas em debate, teorias em construção. Fortaleza: Imprensa Universitária UFC, 2008.

SOUSA SANTOS, Boaventura. A gramática do tempo: por uma nova cultura política. São Paulo: Cortez, 2008.

TENÓRIO, Fernando G. A trajetória do Programa de Estudos em Gestão Social (Pegs). Revista Administração Pública, v. 40, n. 6, p.1145-1162, nov./dez. 2006.

ULLRICH, Danielle Regina. A construção de saberes no campo da cooperação internacional sul-sul à luz dos postulados e princípios da gestão social. Porto Alegre:

UFRGS, 2014. 190 f. Tese (Doutorado em Administração) - Programa de Pós-Graduação em Administração, Universidade Federal do Rio Grande do Sul, Porto Alegre, 2014 .

WALLERSTEIN, I. World-system analysis: an introduction. London: Duke University Press, 2004.

XALMA, C. Report on South-South Cooperation in IberoAmerica 2011. Madrid: Ibero-American General Secretariat (SEGIB), 2011. 


\section{INTERNATIONAL COOPERATION MANAGEMENT FOR THE SOUTH-SOUTH DEVELOPMENT ACCORDING TO THE POSTULATES AND PRINCIPLES OF SOCIAL MANAGEMENT}

\author{
Danielle Ullrich \\ Rosinha Carrion
}

\section{GESTION DE LA COOPÉRATION INTERNATIONALE POUR LE DÉVELOPPEMENT SUD-SUD SELON LES POSTULATS ET LES PRINCIPES DE LA GESTION SOCIALE}

\author{
Danielle Ullrich \\ Rosinha Carrion
}

This theoretical essay discusses the nature of the relationships between countries in the international system and their respective implications on the management of programs and projects in the field of international cooperation and development (ICD), according to the postulates and principles of social management. We start from the premise that the ICD actions implicate management processes and are influenced by the idea the donor country has of development, as well as its reasons for cooperating. The Science of Administration and, in particular, social management, has much to contribute for the understanding of the results and review of management practices that follow actions performed by ICD. The practice of imposing and overrating "technical knowledge", instead of "local knowledge", technical and non-technical, considered to be inferior, has been causing disastrous results, politically, economically and socially.

KEYWORDS: International cooperation and development. South-South Cooperation. Social Management. Construction of knowledge. Ecology of knowledge.
Cet essai théorique traite de la nature des relations existantes entre les pays au sein du système international et leurs incidences sur la gestion des programmes et des projets dans le domaine de la coopération internationale pour le développement (CID), à la lumière des postulats et des principes de la gestion sociale. Il part du principe que les actions de la CID supposent des processus de gestion et sont influencées par la représentation que le pays donateur se fait du développement, tout comme des motivations qui le conduisent à coopérer. La Science de la Gestion, et tout particulièrrement la gestion sociale, peut considérablement contribuer à la compréhension des résultats et au remaniement des pratiques de gestion qui accompagnent les actions réalisées dans le cadre de la CID. La pratique qui consiste à imposer et à mettre beaucoup plus en valeur les "savoirs techniques" au détriment des "savoirs locaux”, qu'ils soient techniques ou non, considérés comme inférieurs, a conduit à des résultats désastreux en termes politiques, économiques et sociaux.

Mots-CLÉs: Coopération Internationale pour le Développement. Coopération Sud-Sud. Gestion sociale. Construction de savoirs. Ecologie de savoirs.

\footnotetext{
Danielle Ullrich - Doutora em Administração. Professora do Instituto Federal de Santa Catarina (IFSC). Membro do Grupo de Estudos e Pesquisas em Empreendedorismo e Inovação (GEPEI/IFSC). Tem experiência nas áreas de Administração, Cooperação Internacional para o Desenvolvimento, Planejamento Urbano e Regional e Turismo, atuando principalmente nos seguintes temas: organizações, planejamento, cooperação, desenvolvimento local, regional e internacional, gestão social, turismo e responsabilidade social. Publicações recentes: A Cooperação brasileira na área da educação nos Palops no período 2000-2012: principais atores e projetos. Revista Sociais e Humanas, v. 27, p. 146-160, 2014; Em análise a Cooperação Sul-Sul: ruptura ideológica ou reprodução?. Política \& Sociedade (Impresso), v. 12, p. 65-84, 2014; Em análise a Cooperação Sul-Sul: um novo padrão de relações internacionais?. Revista de Geopolitica, v. 5, p. 82-98, 2014.

Rosinha Carrion - Doutora em Administração. Professora Titular da Universidade Federal do Rio Grande do Sul. Pos-Doutora pelo Institute de Recheche Pour le Développement (IEDES/Université I / Sorbonne/2010). Membro Permanente do Programa de Pós-Graduação em Administração (PPGaqUFRGS). Coordena, na UFRGS, o Núcleo Interdisciplinar de Pesquisa e Estudos sobre o Terceiro Setor (NIPETS/ PPGA/UFRGS/ 1999. Atua em Pesquisa nas áreas de Gestão Social; Gestão de Pessoas; Organizações, Sociologia Política e Relações Internacionais. Tem por principais temas: Globalização; Política de Cooperação Internacional; Cooperação para o Desenvolvimento de Países Periféricos; Processos de Construção Democrática; Movimentos Sociais, Organizações Não Governamentais; Organizações Internacionais; Gestão de Cidades. Publicações recentes: Sobre a governança da cooperação internacional para o desenvolvimento: atores, propósitos e perspectivas. Revista de Administração Pública (Impresso), v. 46, p. 1847-1868, 2014; Em análise a Cooperação Sul-Sul: ruptura ideológica ou reprodução?. Política \& Sociedade (Impresso), v. 12, p. 65, 2014; A cooperação Sul-Sul como um novo padrão de relações internacionais? O Caso do Acordo de Cooperação Técnica entre UFRGS (Brasil) e Uni-CV (Cabo Verde). Revista de Geopolitica, v. 5, p. 82-98, 2014.
} 
